\title{
A case of successful learning about magnetism through the use of evidence
}

\author{
Tamara G. Young \\ Physics \& Astronomy, University of Utah, 115 S. 1400 E. 201 JFB, SLC, UT 84112 \\ Lauren A. Barth-Cohen \\ Educational Psychology, University of Utah, 1721 Campus Center Dr. SAEC 3220, SLC, UT 84112
}

Sarah K. Braden and Sara Gailey

School of Teacher Education and Leadership, Utah State University, 2805 Old Main Hill, Logan, UT 84322

This paper explores the remarkable success of one 7 th grade student as she discovers foundational concepts while engaging in an NGSS-aligned unit on modeling magnetism. Student success in modeling is of particular interest in the PER community. Through understanding how students are able to create mechanistic models, we can reveal core practices which in turn can be used to inform instructional design. Here we examine one student who was able to synthesize the key concepts of magnetism: that a magnet is comprised of microscopic magnetic dipoles and that the orientation of these dipoles determines the orientation of the macroscopic polarity. We present significant excerpts of the progression of the modeling process in order to illustrate the key factors that affect her learning: her iterative use of evidence to guide her reasoning, her use of prior knowledge, and the interactions with her teacher and peers. 


\section{INTRODUCTION}

This paper focuses on the experiences of a single student who, through the process of model building, is able to discover the microscopic mechanism of magnetism for herself. Understanding magnetism is something that is difficult for students [1-4]. This student's success is notable due to her sophisticated use of evidence to guide her reasoning. The student was able to determine the mechanism by which magnetism works at a microscopic level by interacting with the physical phenomena, by using prior knowledge of attractive and repulsive forces, and through engaging in questioning with her peers and her teacher. In this paper we explore how this is accomplished.

\section{BACKGROUND AND THEORETICAL FRAMEWORK}

Within PER, there is a traditional approach of focusing on students' misconceptions or learning difficulties [5]. This approach has well-documented benefits in supporting the design of instruction [6]. Yet, there are important reasons to focus on cases of students' learning successes. By looking at students' unique pathways to achieving understanding we can document the factors that contribute to this and in turn, develop instruction to support other students' successes.

Student success in modeling is of particular interest to the PER community. Modeling is considered important in physics [7, 8], in part because reasoning through modeling can be productive for student learning and conceptualizing evidence [9]. However, research in modeling has often focused on difficulties: Students are often more concerned with how a model looks than what a model does [10] and can have challenges with applying models from one context to another $[11,12]$. Furthermore, some of the PER work related to modeling has documented success through quantitative outcome measures [13-16], but less work has examined the learning pathways towards success [17].

This research is situated in the resources framework [18], which is a way of understanding how students use prior knowledge in sensemaking. Existing work within this perspective has examined students' prior knowledge as a resource for future learning, along with pathways and learning mechanisms that can support success [19-21]. This perspective forms our theoretical background as we examine one student's sensemaking about magnetism.

\section{METHODS}

\section{A. Instructional Setting}

This research is part of a larger study on middle-grade students modeling magnetism. The curriculum was developed as a collaboration between researchers and two 7th-grade teachers. One of the collaborators, Dr. Streatfield (a pseudonym), taught 7 th-grade integrated science at a Title 1 charter school focused on science education. The curriculum was designed to align with the NGSS scientific practice of Developing and Using Models and the disciplinary core idea of Types of Interactions [22], which in this instance involved a focus on how magnetic forces are able to act over distances. Similar curricula can be found in the literature [3, 4].

During the two weeks of instruction, students in small groups worked to create a model to explain what is happening in an anchoring phenomenon, a floating paperclip. Students participated in the following instructional sequence: explored the phenomenon, created an initial model, interacted with eight lab stations to observe other aspects of magnetism and collect relevant evidence, revised their models, then used consensus building activities to create a final model that they presented to the class. The teacher engaged with the students during this process, asking questions and highlighting results, to lead students to a model that explained magnetism and that enabled them to make predictions. Importantly, as an NGSS aligned modeling unit, there was no direct instruction on magnetism prior to or during this lesson.

\section{B. Data Collection and Role of the Researcher}

Data consist of the following: researcher written field notes; audio recordings of the entire class, including both small group work and whole class discussion; video of selected small group work and whole class discussions; and copies of the groups' final paper models and final individual students' magnetism assessments. During the instruction there were between one and three researchers in the room to collect data and support the teacher, interacting with the students when requested by Dr. Streatfield.

\section{Analysis Methods}

Field observations indicated that the richest data was in the whole class presentation of the final model, so we transcribed this first. Pseudonyms are used throughout this paper. We wrote narratives describing each group's final model with a focus on mechanistic reasoning and scientific accuracy. We selected one focal group based on the clarity and success of the final model and associated presentation. One student in this group, Addie, provided a notably correct explanation of magnetism, although the representation was not canonical. We then transcribed the remaining audio and video for Addie's group, resulting in complete audio and partial video for this group over the entire instruction.

From the transcripts, we analyzed the data using narrative analysis techniques. Narrative analysis, in this situation, is a method of creating a narrative by synthesizing and emplotting events and actions to create a coherent whole [23]. This technique includes aspects of discourse analysis [24]. In this case, a narrative approach was used to examine the entirety of 
Addie's reasoning and unpack how early events contributed to her final model. Specifically we focused on key points in time that contained relevant confusions, progress that was impacted by new evidence, and key teacher initiated scaffolds, which are presented below. In the transcripts, specific words and phrases are bolded to highlight these elements.

\section{NARRATIVE ANALYSIS}

In this analysis, we consider three episodes, in chronological order 1,2, and 3, and two artifacts. We will begin with an analysis of the artifacts, Addie's part of her groups final model and Addie's assessment, to show her learning outcome: The macroscopic phenomenon of magnetism is explained by microscopic magnetic dipoles (polarity) and the orientation of the dipoles. This allows for the correct prediction of macroscopic behavior when the microscopic dipoles are changed (for example, by breaking the magnet). Concurrently, we consider episode 3 , the final class presentation of the group model, in which Addie explains how she came to this understanding. Next we will investigate two earlier episodes: The first episode is key to her sensemaking about the microscopic dipoles and the second one examines her sensemaking about the orientation of the dipoles. Both of these episodes contribute to her ability to make correct predictions about changing the orientation of the dipoles.

\section{A. Episode 3: Final Understanding as Captured in the Final Model, Assessment, and Final Group Presentation}

This section focuses on Addie's learning and contributing factors. Addie's learning is demonstrated by the section of the final model that she created, as well as her final assessment (see Figs. 1-2). These artifacts show that Addie has generated a model in which a permanent magnet is comprised of dipolar microscopic units and the orientation of these dipoles determine the orientation of the magnet. Examining Addie's part of the group model, the magnet in the "thought bubble" (see Fig. 1), we see that "molecules" in the magnet are represented by ovals with pluses and minuses, the students explain this represents the "polarity" of the magnets. Also significant is how the dipoles are oriented vertically in the disk magnet, such that the positive end is at the top, labeled north, and the negative end is on the bottom, labeled south. In Addie's final assessment, she has changed the pluses and minuses to $\mathrm{N}$ and $\mathrm{S}$, (see Fig. 2) which is more canonical, but has retained both the polarity and the orientation.

In the group presentation, at the front of the class, Addie describes how she she is able to determine the dipole nature of the "molecules" that make up the magnets, as well as how she was able to figure out the orientation of the dipoles. Finally, she makes a prediction about what happens when she breaks the magnet. All transcripts in this paper have been edited for clarity while maintaining the voices of the participants.

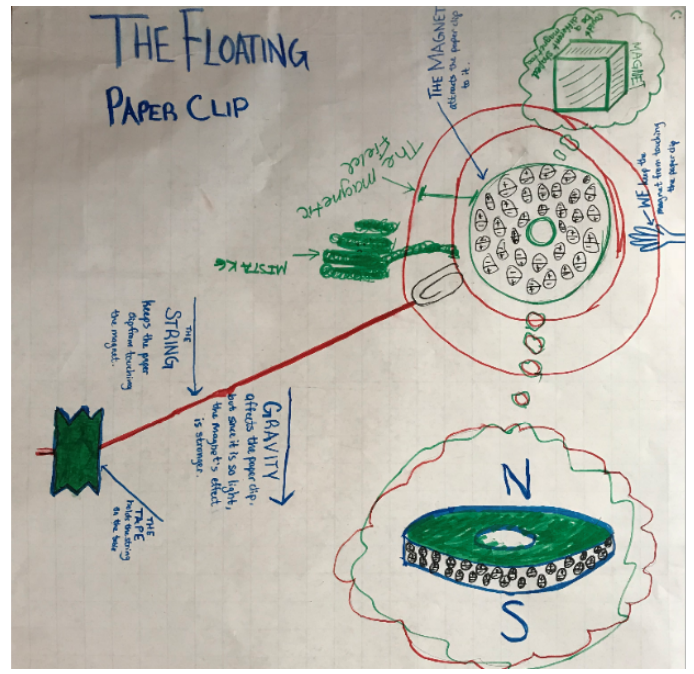

FIG. 1. Addie's group's final model showing the floating paperclip, the magnetic field and the dipole "molecules" that comprise the magnet.

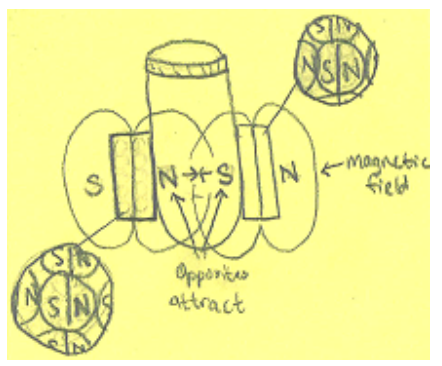

FIG. 2. Section of Addie's final assessment, which asks what is happening in and around two magnets that are sticking to the sides of an empty glass tube, showing the dipoles that comprise the magnets.

1. Addie: So we have the molecules in the magnet and then we have it [the magnet] from the side <pointing at the "thought bubble" magnet>. I was really confused how the molecules are drawn. And so I was thinking: which side is north? and then which is south?. And I was playing with some bar magnets $<$ moves her hands as if she is putting the bar magnets together $>$. And I set them together with the side, and then I flipped them over and [they] didn't stick together <turns her hands around, indicating how the magnets flipped over, pauses, turns to the board $>$. Can I draw?

2. Dr. Streatfield: Yeah, totally, make sure you draw nice and big though.

3. Addie: <off camera $>$ I just had them from the side and they stuck together. And then this is the top and this the bottom. And with this one [turned] over, right there, then they didn't stick together. And that's what made me think, instead of like this, the north is the top and 
the south is the bottom. So that's why, we have them here and here.

4. <...several minutes of non-related class discussion...>

5. Andrea: <off camera > So in your magnet, you have a molecules kind of thing. And they have, it looks like, a negative and a positive side? What's the story behind that?

6. Addie: When we were breaking the magnets, it didn't fit together, and I was so confused. And then [initially] I was thinking that some atoms were positive and some were negative. And then I decided that they were like split in half. So, they didn't break the magnet and they get together $<$ pauses $>$...

7. Evan: It's basically a way to demonstrate the polarity $<$ pointing at the poster>.

8. Addie: Oh! I know what I was going to say. If you break the magnet, then it always has a north and south pole <gesturing top and bottom $>$. Cause the atoms have a north and south side <gesturing above and below $>$. Yeah $<$ smiles $>$.

While narrating her drawn model, Addie expresses confusion about the orientation of the dipoles in the model (line 1) and that she determined the orientation through evidence obtained by interacting with bar magnets (line 1). The evidence she describes is how the magnets will stick together one way, but not stick together when one magnet is flipped over (line 3). Later Addie describes being confused by the evidence that a broken magnet does not fit back together when broken (line 6). She explains that she resolves this confusion by determining that the "atoms" in the magnet are "split in half" ie. dipolar, rather than some are "positive" and some are "negative" (line 6). Finally, Addie makes a prediction that when a magnet is broken, both the magnet and "atoms" have north and south sides (line 8). In this episode, Addie uses evidence to work through confusion to reach a greater understanding, and then applies that understanding to make a prediction.

\section{B. Episode 1: Sensemaking about Polarity}

In this episode, we examine Addie's sensemaking about polarity. This occurs in the first half of the two week curriculum, prior to the final presentation, but after the students had explored four of the eight stations. Importantly, this takes place immediately after Addie's group visited the station where they intentionally broke a magnet. Below, Addie explains her most recent model to Dr. Streatfield, which includes the dipole "molecules." Dr. Streatfield then provides scaffolding to encourage Addie to think about predictions she could make with her model.

1. Addie: I have a new theory about the other station.

2. Dr. Streatfield: Oh okay, so this is station 6 [the broken magnet station]? Okay?

3. Addie: I'm thinking each molecule [has] one side and the other side. And then, if you split it in half, the magnet always has two poles, because the molecules <in- audible>.

4. Dr. Streatfield: I think that's a wonderful explanation.

5. Dr. Streatfield: So would it be different if I split the magnet this way <indicating top and bottom> or if I split the magnet this way <indicating right and left $>$, how the halves go back together? So, what if I split the magnet this way <indicating top and bottom $>$, what's left on this edge <pointing to the bottom edge $>$ ?

6. Addie: The negative.

7. Dr. Streatfield: And what's left on this edge <pointing to the top edge $>$ ?

8. Addie: The positive.

9. Dr. Streatfield: K. So what do you think will happen to those two edges? What happens if I broke it this way $<$ indicating right and left $>$ ? What's left here $<$ pointing to the left edge>? What's left here <pointing to the right edge $>$ ?

10. Addie: Ooooo! that's why the magnet is <inaudible $>$ together.

11. Dr. Streatfield: So, do you think with this kind of thinking you could pick out, what was the... So do you think you could figure out which is north and which is south on this [disk magnet]? So is it north/south $<$ pointing to the top and bottom>, or is it north/south $<$ pointing to opposite edges $>$ ? That's your next mystery, you've done so well, I bet you could figure it out. Initially Addie asks Dr. Streatfield to look at her new model, in which she describes each "molecule" having two poles, the same way the magnet does (line 3). Dr. Streatfield then asks Addie to make predictions about what would happen if you broke the magnet different ways (line 5), providing scaffolding to push Addie to use her model to make these predictions (lines 5-9). Addie's exclamation suggests that she understands what is happening with her model (line 10), which leads Dr. Streatfield to ask for another prediction about the location of the poles on the disk magnet (line 11). This episode is significant because Addie alludes to of the use of evidence about breaking magnets in her sensemaking and because of the scaffolding Dr. Streatfield provided to help Addie think about using the model to make a prediction.

\section{Episode 2: Determining Orientation}

In this episode, Addie and the other students use a disagreement, evidence, predictions, and questions from Dr. Streatfield to come to an understanding about the orientation of the magnetic poles and the "molecules" in the magnet. This episode occurs on the penultimate day of instruction as the students are drawing their group model, the day before the final presentation. Below, the students are disagreeing about how to orient the "molecules." To help resolve this disagreement, Dr. Streatfield asked the students to make predictions with their models and use evidence to support their models. Importantly, she provided them with a means to collect additional evidence, and this new evidence supported the students 
coming to a new agreement about the disk magnet.

1. Dr. Streatfield: The other thing you show me [is] pluses and minuses on this side, and minuses and pluses on this side. What evidence do you have for that?

2. Addie: I don't really understand why Evan drew it like that?

3. Dr. Streatfield: How would you put it?

4. Addie: I would just put it all the same because there is a north pole and a south pole.

5. Lucia: I don't know, I'm just assuming... I can see why he did that though, because he did say that if you broke this magnet in half, you wouldn't be able to put it back together.

6. <...Dr. Streatfield encourages the students to compare the models and make predictions using the models...>

7. Dr. Streatfield: Well, let's say, where's the positive pole? Where's the negative pole? So yours definitely has an orientation, does Evan's have an orientation?

8. Addie: Not really, but like with mine... If you break it one way then that repels but if you break it another way that attracts.

9. Dr. Streatfield: So maybe neither of these are perfect. So far whose makes the most sense given the evidence? I'm going to show you some bar magnets.

10. <...Dr. Streatfield leaves and returns with the magnets. Dr. Streatfield encourages the students to label their models and draw the magnets from different angles...>

11. Addie: I wish we could break a magnet this way.

12. Dr. Streatfield: Ooh, what do you think you'd see if you broke it that way?

13. Addie: I think they'd attach, I'm not sure.

14. Dr. Streatfield: Can you draw it out for these guys? See if you can give them some evidence and help them walk through your thinking?

15. Addie: So, they'd attach like this, but then I flip it and it does not attach. So that makes me think that this is the side of the magnet. I think it's split like that. See what I'm saying? I was just, I was doing it upside down.

While the students are disagreeing about the orientation of the microscopic dipoles, Dr. Streatfield stops to ask for evidence (line 1). Addie and Lucia provide contradictory evidence (lines 4 and 5). Dr. Streatfield nudges the students towards resolving this disagreement by proposing ways of comparing their models and encouraging them to make predictions. Addie is concerned because her model predicts the magnet should go back together if broken one way but not if broken another way (line 8). Dr. Streatfield recognizes the confusion and provides important scaffolding by encouraging the students to use evidence obtained from bar magnets (line 9). This allows Addie to recognize the different behavior of the two types of magnets (line 13), and that her model is correct (line 15). Thus, during this pivotal moment, the disagreement is resolved through the inclusion of additional evidence and predictions.

\section{DISCUSSION}

This case shows how a 7th grade student used a modeling approach to determine foundational ideas about magnetism that the literature says is difficult even for older students and adults [1, 2], for example, many adults have a monopolar mental model of magnetism [25]. Importantly, this student was able to deduce that the microscopic parts that make up magnets are dipoles and that the orientation of the dipoles determines the orientation of the poles for both bar magnets and disk magnets. She then used this knowledge to make a prediction about breaking a magnet.

The pathway that this student took to come to this understanding uses her own confusions, evidence and supporting scaffolding from the teacher. Addie initially thought that the "atoms" in the magnet were monopoles, but this idea failed to explain the behavior of the broken disk magnet. This confusion led to her developing a model that included dipole "atoms." After explaining this model to Dr. Streatfield, Dr. Streatfield encouraged her to make some predictions about what would happen if her model was broken one way vs. another way, then encouraged her to determine the location of the poles on a disk magnet.

Addie was confused about how the poles are oriented on a disk magnet. She explained that she determined the orientation of a disk magnet by comparing the behavior of a disk magnet to the behavior of a bar magnet. We find that this exploration with bar magnets occurred during a disagreement within her group about how to orient the dipoles. The resolution of this disagreement resulted in her correctly identifying the poles of the disk magnet, and drawing the microscopic dipoles to align with the macroscopic dipoles. Finally, Addie uses her model to make a correct prediction about breaking a magnet.

As a single case study, this work is important for documenting what is possible with using a modeling approach to learn about magnetism. Here we showed that this success occurred through the thoughtful use of evidence along with additional supports in the form of discussion and disagreements with others. The literature has documented the importance of modeling in physics instruction [7-17], but less work has documented pathways of how this success occurs and relevant factors. Here we showed the importance of key evidence in contributing to this instance of successful learning. Open questions remain about how this experience differs from that of Addie's peers or from similar experiences with undergraduate or elementary learners.

\section{ACKNOWLEDGEMENTS}

We thank the students and teachers who opened their classroom and embraced this collaboration. We also acknowledge José Gutiérrez for early feedback and recommendations. 
[1] J. Guisasola, J.M. Almudi, and J.L. Zubimendi, Science Education, 88, 443 (2004).

[2] M.H.P. Kesonen, M.A. Asikainen, P.E. Hirvonen, Euro. J. Phys., 32, 521 (2011).

[3] M.F. Cheng, and D.E. Brown, Journal of Research in Science Teaching, 52, 1053 (2015).

[4] D.B. Harlow, Science Education, 94, 142 (2010)

[5] C.H. Kautz, P. R. Heron, M.E. Loverude, and L.C. McDermott, Am. J. Phys., 73, 1055 (2005).

[6] L.C. McDermott, P.S. Shaffer, Tutorials in introductory physics. (Pearson Learning Solutions, New York, 2012).

[7] B.M. Zwickl, D. Hu, N. Finkelstein, and H.J. Lewandowski, Phys. Rev. ST Phys. Educ. Res., 11, 020113 (2015).

[8] E. Etkina, A. Karelina, and M. Ruibal-Villasenor, Phys. Rev. ST Phys. Educ. Res. 4, 020108 (2008).

[9] R.S. Russ and T.O.B. Odden, Phys. Rev. Phys. Educ. Res. 13, 020105 (2017).

[10] M. Windschitl, J. Thompson, and M. Braaten, Science Education, 92, 941 (2008).

[11] J.T. Stanley, W. Su, and H.J. Lewandowski, Phys. Rev. Phys. Educ. Res. 13, 020127 (2017).

[12] M. Vonk, P. Bohacek, C. Militello, and E. Iverson, Phys. Rev. Phys. Educ. Res. 13, 020106 (2017).

[13] E. Brewe, L. Kramer, and G. O’Brien, Phys. Rev. ST Phys. Educ. Res. 5, 013102 (2009).

[14] E. Brewe, V. Sawtelle, L.H. Kramer, G.E. O'Brien, I. Rodriguez, and P. PamelÂ $\tilde{i}_{i}$, Phys. Rev. ST Phys. Educ. Res. 6,
010106 (2010).

[15] A. Karelina and E. Etkina, Phys. Rev. ST Phys. Educ. Res. 3, 020106 (2007).

[16] A. Leniz, K. Zuza, and J. Guisasola, Phys. Rev. Phys. Educ. Res. 13, 010128 (2017).

[17] A.A. diSessa, B. Sherin, and M. Levin, in Knowledge and interaction: A synthetic agenda for the learning sciences edited by A. diSessa, M. Levin, and N.J.S. Brown (Routledge, New York, 2016), p. 30.

[18] D. Hammer, Am. J. Phys., 68, S52 (2000).

[19] L.A. BarthâCohen, M.C. Wittmann, Science Education 101, 333 (2018).

[20] O. Parnafes, Journal of the Learning Sciences, 16, 415 (2007).

[21] A.A. diSessa, Cognitive Science, 38, 795 (2014).

[22] NGSS Lead States, Next Generation Science Standards: For States, By States, (2013), Appendix F.

[23] D.E. Polkinghorne, International Journal of Qualitative Studies in Education, 8, 5. (1995).

[24] M. Savin-Baden, C.H. Major, Qualitative Research: The essential guide to theory and practice, (Routledge, New York, 2013), p. 444.

[25] F. Goldberg, S. Robinson, and V. Otero, Physics and Everyday Thinking, (It's About Time, Armonk, 2006) 